\title{
Contraindication and End Point of Gastrografin Trial in Adhesive Small Bowel Obstruction
}

\author{
Aswini Kumar Misro • Naim Kadoglou
}

Received: 20 November 2013 / Accepted: 28 February 2014 / Published online: 9 March 2014

(C) Association of Surgeons of India 2014

\begin{abstract}
It is important to know the contraindication and end point of Gastrografin trial in adhesive small bowel obstruction.
\end{abstract}

Keywords Bowel · Obstruction · Abdomen · Surgery · Gastrografin

\section{Dear Editor}

We read the article titled "Prospective Evaluation of Oral Gastrografin ${ }^{\circledR}$ in the Management of Postoperative Adhesive Small Bowel Obstruction" with profound interest as we regularly use in our centre the oral Gastrografin in the management of adhesive small bowel obstruction as per the merit of each case. As this article is available freely in PubMed, it gives us the opportunity to access and read it easily. Here, I take the liberty to highlight a few points that we think might be relevant in the context of this article.

In addition to the exclusions mentioned in the article, it is important to identify few other groups of patients who may not befit a trial of therapeutic Gastrografin. It is very important to carry out an appropriate investigation to rule out closed bowel loop obstruction, as delayed diagnosis will only exacerbate the problem.

Any patient showing an evidence of peritonism or hollow viscus perforation should proceed for immediate surgery. Lastly, overwhelming sepsis, persistent metabolic acidosis (despite rehydration), high and persistent base deficit and impending or established organ failure should also be excluded from this trial.
I would like to make the following comment with regard to the end point of the trial. Our current practise is to wait for $4 \mathrm{~h}$ for the Gastrografin to reach the caecum; failing which, surgical exploration is more likely sooner rather than later [1,2]. Although conservative management can be carried out for days together, the failure of the contrast to reach the large bowel within 24-36 h mandates an assessment of a clinical condition to determine the need for a possible surgical intervention.

\section{References}

1. Srinivasa S, Thakore N, Abbas S, Mahmood M, Kahokehr AA, Hill AG (2011) Impact of gastrografin in clinical practice in the management of adhesive small bowel obstruction. Can J Surg 54(2):123-127

2. Di Saverio S, Coccolini F, Galati M, Smerieri N, Biffl WL, Ansaloni L, Tugnoli G, Velmahos GC, Sartelli M, Bendinelli C, Fraga GP, Kelly MD, Moore FA, Mandalà V, Mandalà S, Masetti M, Jovine E, Pinna AD, Peitzman AB, Leppaniemi A, Sugarbaker PH, Goor HV, Moore EE, Jeekel J, Catena F (2013) Bologna guidelines for diagnosis and management of adhesive small bowel obstruction (ASBO): 2013 update of the evidence-based guidelines from the world society of emergency surgery ASBO working group. World J Emerg Surg 8(1): 42. doi:10.1186/1749-7922-8-42

\section{Sources of Funding for Research and Conflict of Interest}

No Funding for the Research or Conflict of Interest.

A. K. Misro $(\bowtie) \cdot$ N. Kadoglou

Dept of Surgery, Ealing NHS Trust, London, United Kingdom

e-mail: draswini@gmail.com 